\title{
A Gestão da Força de Trabalho em Saúde na Década de 90
}

LARISSA DAHMER PEREIRA ${ }^{1}$

Este ensaio objetiva traçar um panorama da gestão da força de trabalho na área de saúde pública nos anos 90, no plano nacional. A questão é tratada a partir do que se considera mais problemático na fragilização do Estado brasileiro e na gestão da força de trabalho, isto é, sua terceirização. Partese do princípio de que a referida década se caracterizou por um processo de reversão das conquistas sociais consagradas na Constituição Federal de 1988. Busca-se apreender, através de estudo bibliográfico, como se efetivou o processo de flexibilização das relações de trabalho na área de saúde pública na década de 90, que reúne um conjunto de estratégias, dentre as quais a desarticulação dos trabalhadores e a desqualificação do atendimento ao público - o que vem sendo denominado por alguns autores de reforma informal do Estado na área de saúde pública. Por último, são tecidas algumas considerações acerca das possibilidades de reversão daquele processo no Governo Lula, com a afirmação de uma saúde pública, gratuita e de qualidade.

Palavras-chave: Saúde pública; força de trabalho; terceirização. 


\section{Introdução}

Este ensaio objetiva traçar, através de estudo bibliográfico, um panorama da gestão da força de trabalho na área de saúde pública no curso da década de 1990, no plano nacional. Particularmente, tratamos a questão a partir do que consideramos mais problemático na fragilização do Estado brasileiro e na gestão da força de trabalho, isto é, sua terceirização.

Partimos do princípio de que essa década se caracterizou por um processo de reversão das conquistas sociais consagradas na Constituição Federal de 1988. Ou, como Behring (2002) nos indica, tratou-se de deflagrar um processo de contra-reforma no país, o que significou:

"um salto para trás, sem o sentido da ampliação das possibilidades de autonomia ou de inclusão de segmentos no circuito 'moderno', diferente das transformações estruturais anteriores, apesar dos limites também destas últimas. Esse retrocesso é o que configura uma contra-reforma, onde há quebra de condições historicamente construídas de efetivas reformas, dentro de um processo mais amplo de profundas transformações" (BEHRING, 2002, p. 6).

A autora nos indica ainda alguns exemplos de desmonte do Estado no Brasil, na perspectiva de adaptação do país à dinâmica do capitalismo contemporâneo: a flexibilização nas relações de trabalho, as privatizações e sua relação com o capital estrangeiro, e os ataques à Seguridade Social pública.

Consideramos de fundamental importância - principalmente ao assumir a direção governativa do país um novo governo que se propôs a redefinir o direcionamento dado às políticas sociais e, também, à política econômica apreender como se efetivou o processo de flexibilização das relações de trabalho na área de saúde pública na década de 1990. Tal processo reúne um conjunto de estratégias, dentre as quais a desarticulação dos trabalhadores e a desqualificação do atendimento ao público - o que vem sendo denominado por alguns autores de reforma informal do Estado na área de saúde pública (NOGUEIRA, 1996).

Com tal balanço, acreditamos ser possível avançar para uma análise crítica acerca da gestão da força de trabalho no Governo Lula e avaliar se houve ou há indicativos de mudanças na gestão da força de trabalho na área de saúde pública. Isso não é propriamente objeto do presente artigo, mas indicaremos 
algumas das ações realizadas pelo atual governo na temática trabalhada.

O setor saúde detém importante parcela da população economicamente ativa deste país ${ }^{2}$. Como parte do setor terciário, tem a característica de, mesmo com o incremento tecnológico, apresentar um dinamismo de crescimento, principalmente se comparado ao mercado de trabalho em geral (VIEIRA, 1998).

Paim (1994, p. 5) apresenta distintos significados para o termo recursos humanos, como: pessoal de saúde; força de trabalho em saúde; categorias profissionais; agentes; e trabalhadores de saúde na área de saúde pública. Todas estas noções/conceitos "referentes aos Recursos Humanos [...] procuram, portanto, valorizar o componente trabalho. Conseqüentemente trazem para a reflexão [...] toda a problemática atinente ao "mundo do trabalho"”.

No presente trabalho, utilizamos a designação força de trabalho em saúde na direção de Paim (1994, p. 64):

"[com] a compreensão dos Recursos Humanos como força de trabalho na sua dupla dimensão 'mercadoria' específica com desvantagem estrutural e ator social capaz de fazer história - além de 'sujeito-agente' das práticas de saúde, eticamente comprometido com a vida e com a redução do sofrimento humano, implica a superação da idéia de meros insumos da função de produção. Já não bastam os enfoques da administração, do planejamento normativo, de teoria do capital humano. Seus problemas também não são redutíveis à gestão do trabalho, ao planejamento estratégico, à economia política”.

E, para a designação trabalhadores de saúde, baseamo-nos na definição de Médici (apud PAIM, 1994, p. 5):

"todos aqueles que se inserem direta ou indiretamente na prestação de serviços de saúde, no interior dos estabelecimentos de saúde ou em atividades de saúde, podendo deter ou não formação específica para o desempenho de funções atinentes ao setor".

Desde a promulgação da Lei Orgânica da Saúde (leis nº ${ }^{\circ} .8080$ e 8.142/90), a questão da força de trabalho em saúde no Sistema Único de Saúde (SUS) tem sido apontada como um dos seus nós críticos, sem, com isto, merecer o devido tratamento no que diz respeito à sua organização e gestão em nível nacional.

Após mais de uma década da promulgação da Lei Orgânica da Saúde 
não temos - ainda - uma norma operacional ${ }^{3}$ que viabilize uma normatização clara para a gestão dos trabalhadores em saúde, tanto no que diz respeito às condições de trabalho de uma forma geral (formas de vínculo empregatício, carga horária, piso salarial), quanto à formação profissional dos trabalhadores em saúde.

A XI Conferência Nacional de Saúde apontou a necessidade premente de se formular uma Norma Operacional Básica de Recursos Humanos e as dificuldades ${ }^{4}$, no que diz respeito à questão. Apesar das dificuldades apontadas, a gestão da força de trabalho em saúde se efetiva na prática cotidiana dos gestores em saúde, baseada, no entanto, em princípios radicalmente contrários aos preconizados pelo SUS e pelo projeto de Reforma Sanitária.

A década de 1990 é marcada pelo desenvolvimento do projeto de contrareforma do Estado, com a gestão da força de trabalho em saúde através da estratégia de terceirização.

Nogueira (1999b, p. 76) ${ }^{5}$ realiza um balanço do SUS e aponta a realização de múltiplas reformas do Sistema Único de Saúde. Para o autor, estaria ocorrendo uma reforma informal, resumida no quadro por ele denominado de "quadro de flexibilidades":

\section{Quadro de flexibilidades}

\begin{tabular}{|l|l|}
\hline \multicolumn{1}{|c|}{ Reforma oficial } & \multicolumn{1}{c|}{ Reforma informal } \\
\hline $\begin{array}{l}\text { Criação de organizações sociais e agências } \\
\text { executivas sob contrato de gestão. }\end{array}$ & $\begin{array}{l}\text { Terceirização de serviços finais através de } \\
\text { empresas privadas, de cooperativas de } \\
\text { funcionários, cooperativas de agentes } \\
\text { comunitários etc. }\end{array}$ \\
\hline $\begin{array}{l}\text { Possibilidades de reconhecimento das } \\
\text { OSCIP e fixação de termo de parceria. }\end{array}$ & $\begin{array}{l}\text { "Triangulação" através de fundaçães de apoio, } \\
\text { ONGs vinculadas ao Estado e outras } \\
\text { entidades. }\end{array}$ \\
\hline $\begin{array}{l}\text { Flexibilização da estabilidade dos } \\
\text { funcionários. }\end{array}$ & $\begin{array}{l}\text { Criação de entidades privadas não-lucrativas } \\
\text { para gestão de consórcios municipais. }\end{array}$ \\
\cline { 1 - 2 } Permissão de contratos CLT. & $\begin{array}{l}\text { Uso indiscriminado de contratos temporários, } \\
\text { cargos comissionados, "código 7" e artifícios } \\
\text { similares. }\end{array}$ \\
\hline $\begin{array}{l}\text { Admissão mediante processos seletivos } \\
\text { simplificados. }\end{array}$ & $\begin{array}{l}\text { Contratação de pessoal permanente mediante } \\
\text { mecanismos precários, tais como bolsas de } \\
\text { trabalho, pro-labore etc. }\end{array}$ \\
\cline { 1 - 2 } Criação de carreiras de pessoal estratégico.
\end{tabular}


Concordamos com as descrições do autor, quanto ao que está efetivamente ocorrendo no que chama de reforma informal. No entanto, compreendemos que esta faz parte da mesma lógica - neoliberal - da chamada reforma oficial e expressa uma forma de implementação de concepções liberais num país de características históricas como o Brasil. O autor afirma que a reforma informal se realiza sob a formatação das terceirizações e aponta duas formas de terceirização - uma externa, e a outra, interna:

"O contrato de serviços [...] é sempre sinônimo de terceirização [...] há um tipo de relação contratual que tem uma longa tradição no sistema público de saúde no Brasil e que é feito com a iniciativa privada [...] caracterizado pelo fato de o contratado privado entrar na relação utilizando a totalidade dos seus recursos físicos e humanos para prestar os serviços à clientela vinculada ao contratante público [terceirização externa]. O que há de novo na reforma informal [...] é que o contratante cede ao contratado [...] uma parte de seus próprios recursos (materiais e humanos) para prestar o serviço requerido, originando uma semiprivatização [uma terceirização interna]. Na medida em que esses arranjos ocorrem como resultados de negociações internas à organização [...], a legalidade e a impessoalidade do processo licitatório são bastante contestáveis" (NOGUEIRA, 1999b, p. 73-74).

A terceirização nos serviços públicos de saúde é prática recorrente, através dos prestadores de serviços ${ }^{6}$, e também através de contratos por tempo determinado, que passam ao largo das determinações inscritas no Regime Jurídico Único. Além disso, não seguem à risca a expressão "por tempo determinado", visto que muitos contratados permanecem em seus cargos anos a fio, sem a realização de concursos públicos. É o que Cherchglia (1999, p. 382) nos aponta, além da íntima relação entre terceirização e precarização do trabalho:

"Uma forma de contratação temporária [...] é o contrato por tempo determinado, utilizando-se como argumento 'a necessidade temporária de excepcional interesse público'. [...] o que se tem observado é uma prorrogação indefinida [...] em determinadas situações. A terceirização estaria intrinsecamente ligada à precarização do trabalho, pois tem acarretado: menores salários, diminuição dos níveis de proteção social do trabalho, ausência de benefícios ou salários indiretos [...] e níveis mais altos de rotatividade. Um ponto destacado pelos sindicalistas é que a terceirização tem provocado fragmentação e desmobilização dos trabalhadores, com perda de poder de 
barganha dos sindicatos: as negociações perdem seu caráter coletivo para se tornarem localizadas e até mesmo individualizadas. [...] O processo mais geral de precarização das relações de trabalho, na saúde, é evidenciado pelas inúmeras formas de contratação, seja pela terceirização [...] pela ‘cooperativização' do trabalho ou pelo contrato individual por tempo determinado [...]. No setor público de saúde encontramos [...] contratos de trabalho que transitam dentro de um gradiente de nenhuma proteção social até a estabilidade no emprego [...]".

Nogueira (1999) aponta as seguintes questões relativas à gestão da força de trabalho:

1) O quantitativo de pessoal cedido - servidores federais - na descentralização do SUS para os gestores locais diminui a cada dia, o que cria um problema em relação à questão quantitativa e de reposição dessa força de trabalho ${ }^{7}$.

2) Quadros paralelos de pessoal: através da terceirização e cooperativização, criando um quadro de "antiisonomia" entre os trabalhadores em saúde.

3) Pessoal estatutário e suas carreiras: a política federal é de desestímulo à abertura de novos quadros e carreiras de pessoal estatutário.

4) Admissão de celetistas: crescimento dos quadros via vínculo não-estatutário regulado pela Consolidação das Leis do Trabalho, com o Projeto de Lei $\mathrm{n}^{\circ}$ 4.811/98, em tramitação na Câmara, sobre o emprego público, que preconiza o fim da estabilidade da função pública e inclui o celetista no regime de previdência geral, acabando com as aposentadorias especiais.

5) Cargos comissionados e contratos temporários: deveriam ser reservados às funções administrativas, mas muitas secretarias de Saúde vêm utilizando essa forma de vínculo para contratação de pessoal na prestação de serviços de saúde (como no Programa de Saúde da Família, com a contratação de médicos e agentes comunitários).

6) Vinculação informal: através de "bolsas de trabalho" e utilizadas para contratação de profissionais de saúde, o que faz com que o próprio Estado fomente formas informais das relações de trabalho.

7) Cooperativas de profissionais:

“[...] constituem hoje uma presença muito forte tanto no setor privado como público e vêm se transformando numa espécie de agência de fornecimento 
de força de trabalho que negocia seus preços com os gestores e são por eles contratadas diretamente. [...] Se é verdade que, no contexto das dificuldades legais e econômicas atuais, as cooperativas profissionais parecem para o gestor como um mal menor, têm, no entanto, uma desvantagem inegável, que é favorecer a fragmentação das formas de vinculação de pessoal e obrigar que se crie uma grande quantidade de agências com os quais a negociação e as decisões sobre contratos e remuneração têm de ser tomadas caso a caso" (NOGUEIRA, 1999, p. 448).

8) Cooperativas gerenciais: quando o gestor público transfere a unidade de saúde para uma gerência "terceirizada" - caso do PAS em São Paulo e hospitais no Rio de Janeiro -, o que impede qualquer forma de controle do poder público.

9) Termos de parcerias com OSCIPs: a nova lei (Lei $n^{\circ} 9.790,23$ de março de 1999) que reconhece as Organizações Não-Governamentais como Organizações Sociais de Interesse Público (OSCIPs) faculta ao Estado estabelecer parcerias com as mesmas na implementação de políticas administrativas. No entanto, o próprio autor admite que "dada a debilidade histórica de nosso Terceiro Setor, poucos são os municípios que contarão com OSCIPs idôneas e habilitadas para assumir a envergadura dessas tarefas" (NOGUEIRA, 1999, p. 449).

10) Regras gerais de admissão: com as variadas formas de flexibilização das relações de trabalho e de terceirização de pessoal, as regras de impessoalidade e comprovação de méritos são questionáveis, com acusações de clientelismo e personalismo.

Por último, Nogueira (1999b, p. 80) traça os seguintes possíveis cenários para os próximos cinco anos:

- "as organizações sociais são impostas pela força política da reforma oficial e se difundem como a modalidade hegemônica de prática institucional flexibilizada no Sistema Único de Saúde, suplantando as iniciativas da reforma informal (pouco provável, devido a divergências doutrinárias e políticas nos três níveis de governo);

- as terceirizações, pela via das cooperativas e outras soluções similares, difundem-se espontaneamente graças ao processo de reforma informal e tornam-se a forma institucional preferida pelos 
gestores do SUS (pouco provável, pelas mesmas razões mencionadas acima);

- haverá uma mescla de múltiplas soluções de flexibilização institucional e de gestão de pessoal: crescimento das terceirizações internas pela via das cooperativas e de empresas privadas típicas; desenvolvimento do contrato terceirizado externo com clínicas e hospitais privados; fundação de um número limitado de hospitais na qualidade de organizações sociais; consolidação e expansão da linha de parceria com as OSCIPs; adoção ampla das medidas de administração de recursos humanos decorrentes da reforma oficial (cenário mais provável)".

O terceiro cenário perdurou durante a década de 1990, nos Governos Fernando Henrique Cardoso, com a persistência de um cenário de múltiplas formas de contratação, flexibilização e gestão de pessoal, e a perda de direitos trabalhistas, sociais e previdenciários dos trabalhadores em saúde e em geral.

Importante documento para o subsídio da discussão realizada é o "Parecer sobre terceirização e parcerias na saúde pública", do Subprocuradorgeral da República Wagner Gonçalves (1998). O mesmo apresenta o quadro nacional de terceirizações e parcerias na saúde pública e esclarece que, sob a denominação de "convênio", o que realmente está sendo realizado na saúde pública é a terceirização (via contratos) da prestação de serviços na área da saúde pública, em sua atividade-fim. Assim, apresenta a diferenciação entre contrato e convênio:

“[...] a distinção mais precisa entre o contrato e o convênio é quanto à reciprocidade de obrigações (bilateralidade). Enquanto no contrato uma das partes se obriga a dar, fazer ou não fazer alguma coisa mediante pagamento previamente acertado [...], no convênio os interesses são comuns e a contraprestação em dinheiro não precisa existir. O que se faz é ajuste de mútua colaboração para atingimento de objetivo comum" (GONÇALVES, 1998, p. 18-19).

O parecer do subprocurador afirma que o que vem sendo feito na saúde pública é a realização de contratos, através de pagamento, proveniente dos cofres públicos, a setores privados pela prestação de serviços na área de saúde:

"[...] a maioria das organizações sociais [...] que não dispõem de qualquer 
patrimônio ou estrutura hospitalar, ao efetuarem contratos (e não convênios) com a Administração Pública, estão atrás de vantagens pessoais para seus associados que, no mínimo, de servidores públicos passam a gestores da coisa pública (sem licitação ou concurso), obtendo salários melhores e inúmeras outras vantagens, inclusive a possibilidade de se utilizarem da estrutura pública dos serviços de saúde para atendimento de clientes particulares, como é público e notório" (GONÇALVES, 1998, p. 18-19).

O autor posiciona-se contrário à Lei $\mathrm{n}^{\circ} .9637 / 98$, que transfere para a iniciativa privada (sob a denominação de organizações sociais) a prestação dos serviços públicos de saúde, o que é ilegal e inconstitucional, por atentar contra as leis $n^{\circ}$ s. 8.080/90 e 8.152/90. Aponta ainda que o Poder Executivo lançou a Medida Provisória $n^{\circ} 1.591$, transformada na Lei $n^{\circ}$ 9637/98, ignorando os posicionamentos contrários do Conselho Nacional de Saúde e da Federação Nacional dos Médicos ${ }^{8}$ :

"Na realidade, o sentido da Medida Provisória n 1.591/97, que resultou na Lei $\mathrm{n}^{\circ}$ 9.637, de 15 de maio de 1998, é privatizar os serviços públicos, sob alegação de eficiência, modernidade e eficácia. Busca-se implantar, na Administração Pública, o regime de direito privado, tornando-se letra morta o princípio da legalidade, inerente à Administração. Assim, violenta-se o Estado de Direito, e quando o Poder Judiciário determina a observância do referido princípio, os tecnocratas de plantão vêm a público para afirmar que as decisões judiciais 'atrapalham' a modernidade e a necessária Reforma do Estado" (GONÇALVES, 1998, p. 10).

A terceirização proporcionaria, para os defensores da transformação da administração pública burocrática em uma administração pública gerencial ${ }^{9}$, maior flexibilidade para o processo administrativo, com a diminuição de custos para os cofres públicos.

Gonçalves (1998, p. 5-13) apresenta um panorama nacional das formas de terceirização e suas características:

a) Município de São Paulo: realizou a primeira forma de terceirização na saúde, através do conhecido - e polêmico - PAS (Plano de Atendimento à Saúde), com a transferência da unidades de saúde para cooperativas de médicos, responsáveis pela direção, execução e prestação de serviços públicos de saúde.

b) Estado de Tocantins: o Poder Executivo fixou "parceria"/convênio com a 


\section{Sociedade Beneficente São Camilo:}

"A característica básica da terceirização no Estado de Tocantins [...] é a concessão de uso de bem imóvel de determinado hospital [...], com cessão de equipamentos e acessórios que guarnecem o mesmo, concessão de veículos, inclusive, cessão de pessoal técnico especializado [...], pessoal administrativo, para o fim específico de prestação de serviços na área do SUS, transferindo-se-lhe (à São Camilo) também os recursos financeiros necessários, mediante a apresentação das faturas dos serviços efetivamente prestados aos usuários do SUS” (GONÇALVES, 1998, p. 8-9);

c) Rio de Janeiro: foi realizada a transferência da administração dos hospitais estaduais públicos para "empresas" e/ou cooperativas que administrem os hospitais, através da Lei Estadual nº. 2.876/97.

"Já foi iniciado o processo de transferência de hospitais pelo Estado tendo a Procuradoria Regional dos Direitos do Cidadão, via ação civil pública, questionada a legalidade da referida terceirização" (GONÇALVES, 1998, p. 9-10).

Vale anotar que, a partir de 1998, o processo de terceirização dos hospitais estaduais via cooperativas começou a ser desmontado, com a abertura de concurso público para provimento de cargos dos funcionários na área da saúde, realizado no ano de 2000.

d) Bahia: através da Lei Estadual n”. 7.027/97, foi instituído o "Programa Estadual de Incentivo às Organizações Sociais”. Assim nos alerta Gonçalves (1998, p. 11):

"Como se vê, a terceirização no Estado da Bahia guarda características próprias, estando mais em consonância com a MP1.591-1/97, hoje Lei Federal $n^{\circ}$ 9637, de 13 de maio de 1998. Não se objetiva, como noutros estados, somente a terceirização da saúde, mas uma parceria com a iniciativa privada (com ou sem fins lucrativos) bem mais ampla".

e) Roraima: através da Lei Estadual nº. 174/97, instituiu-se o Plano de Assistência Integral à Saúde (PAIS), com o objetivo de criar um novo modelo de gestão na área de saúde pública, através do repasse de verbas públicas para que cooperativas de profissionais passem a gerir/executar o sistema público de saúde. 
Gonçalves (1998, p. 13-14) também aponta que o Ministério Público Federal apresentou ação civil pública contra tais formas de terceirização e indica, entre as diferentes formas de terceirizações, os seguintes pontos convergentes:

" $1^{\circ}$ - todas cedem a capacidade instalada em saúde do Estado (na totalidade ou em parte) para que um terceiro, em nome do próprio Estado, execute os serviços de saúde pública;

$2^{\circ}$ - há cessão de prédios, móveis e equipamentos públicos;

$3^{\circ}$ - são repassados recursos públicos próprios do Estado e/ou do Sistema Único de Saúde;

$4^{\circ}$ - as contratações ou convênios, na maior parte, são feitos sem licitação. Em alguns casos, cooperativas de médicos foram criadas especialmente para assumir os serviços públicos de saúde (ex.: Município de São Paulo e o Estado de Roraima);

$5^{\circ}$ - em alguns casos (na maioria) o pessoal também é cedido pelo Estado, sendo nítida a intenção, como no Estado da Bahia, de transferir, para as entidades conveniadas ou contratadas, ou organizações sociais, a responsabilidade pelo pessoal;

$6^{\circ}$ - em todos os contratos ou convênios conhecidos não são exigidas garantias reais ou fidejussórias para a execução dos referidos ajustes;

$7^{\circ}$ - libera-se a empresa ou entidade terceirizada de realizar licitação para compra de material e execução de contratos;

$8^{\circ}$ - todas alegam que o Estado terá o controle e a fiscalização, chegando um Estado (o de Tocantins) a afirmar que tem a gestão da saúde naquela Unidade Federada, "tendo somente transferido a gerência de unidades hospitalares"”.

Quanto às formas de flexibilização das relações de trabalho, Girardi (1996) apresenta uma diferenciação quanto às formas de flexibilização. Existiriam duas famílias de flexibilidades: a flexibilidade defensiva e a ofensiva.

A flexibilidade defensiva seria uma opção de curtíssimo prazo, com a negação de direitos trabalhistas, generalização dos contratos sociais e 
abrandamento da legislação. Esta seria uma opção alinhada aos princípios do neoliberalismo.

Já a flexibilidade ofensiva estaria calcada em princípios socialdemocratas, com horizonte de médio e longo prazos e através da via negocialcoletiva de repactuação da cooperação no trabalho.

No Brasil, a política de gestão da força de trabalho em geral (e, logo, de gestão da força de trabalho em saúde) tem sua direção baseada na estratégia de flexibilização defensiva e, conforme o provável cenário desenhado por Nogueira (1999b), a forma de contrato via cooperativas foi bastante utilizada no período estudado, com as devidas conseqüências para os direitos trabalhistas.

Longe dos ideais cooperativistas ${ }^{10}$, inúmeras cooperativas - conhecidas como "coopergatos" 11 - foram criadas a partir da década de 90 , no contexto de contra-reforma do Estado já aludido, como veículo de tercerização na área da saúde pública e não somente restrita a essa área específica:

"Helnon de Oliveira Crúzio noticia, em dado alarmante e preocupante, fulcrado em informação colhida junto a órgão da Justiça do Trabalho, que dentre as cooperativas abertas nos últimos cinco anos, $90 \%$ foram montadas apenas para burlar a legislação trabalhista e baixar os custos dos impostos" (BITTENCOURT, 2001, p. 77 - nota 66).

O próprio Governo Federal - na figura do Presidente da República passou a apoiar explicitamente a estratégia de criação de cooperativas:

"Precisamos de novas formas de associações que nos ajudem a resolver problemas como o desemprego mundial, conseqüência da globalização e da falta de controle do motor financeiro internacional e da racionalidade econômica. O cooperativismo é um elemento importante para a conquista de um novo Estado de Bem-estar Social. A solução para os impasses dos desafios no mundo contemporâneo passa pelas cooperativas, que repudiam o assistencialismo e vêem no ser humano a força do trabalho digno [...] a cooperativa, empresa com coração, se caracteriza por juntar diretamente na mesma organização dois aspectos fundamentais do desenvolvimento sustentável: a racionalidade econômica e a solidariedade social (Presidente Fernando Henrique Cardoso, discurso divulgado no site das cooperativas)" (BITTENCOURT, 2001, p. 26-27 - nota 8). 
O discurso presidencial torna-se palatável para aqueles cuja leitura permanece na fenomenalidade do cotidiano ${ }^{12}$, com um raciocínio linear tal e qual: Problema ${ }^{\circledR}$ desemprego. Solução ${ }^{\circledR}$ cooperativas = solidariedade social e desenvolvimento sustentável.

A contratação de cooperativas de trabalho tem como principal objetivo a terceirização da prestação de serviços na área da saúde pública, com a concretização dos ideais da contra-reforma do Estado.

A questão central passa pela terceirização dos serviços de saúde, seja via cooperativas, fundações, Organizações Não-Governamentais. Porém, devido à particularidade do funcionamento das cooperativas - a usurpação, com o respaldo jurídico-formal, dos direitos trabalhistas/sociais - estas vêm sendo umas das principais formas de terceirização na saúde pública.

Os participantes da XI Conferência Nacional de Saúde apontaram no relatório a gravidade das formas de "flexibilização" dos recursos humanos e o significado da presença das cooperativas no sistema público de saúde:

"Denunciar a iniqüidade gerada pela estratégia de flexibilização da contratação de recursos humanos para o Sistema Único de Saúde, que resulta também em maior gasto. Devem-se implantar Planos Nacional, Estaduais e Municipais de valorização dos recursos humanos em saúde, dar total apoio à discussão e implantação da Norma Operacional Básica - recursos humanos e implantar Planos de Cargos e Salários específico para a saúde, com dedicação exclusiva. Denunciar a cooperativização, como forma de precarização das relações de trabalho" (CNS, 2001).

O processo de desmonte do Estado brasileiro na área de saúde pública, ao longo da década de 90, conta com uma dupla estratégia: a primeira, mais geral, é a de desmonte da saúde pública, criando uma "universalização excludente", com uma política pública de saúde voltada para os "pobres", considerados não-cidadãos porque não-consumidores.

A segunda estratégia é a de fragmentação dos trabalhadores em saúde - através da terceirização dos próprios - com débeis condições de trabalho, o que, por um lado, dificulta uma organização política unificada e, por outro, desqualifica o atendimento, com profissionais desvalorizados e desmotivados. 


\section{Desafios para a Gestão da Força de Trabalho em Saúde Pública no Governo Lula}

Este trabalho buscou realizar um panorama do tratamento dispensado à gestão da força de trabalho em saúde nos anos de 1990, com o enfoque no processo de terceirização e a consequente precarização das condições de trabalho em saúde.

Em dezembro de 2003, entre os dias 7 e 11 de novembro, ocorreu a XII Conferência Nacional de Saúde, com a participação de cerca de quatro mil pessoas, entre gestores, usuários, militantes e profissionais de saúde. As discussões foram organizadas em dez eixos temáticos, dentre os quais, o eixo sobre o trabalho na saúde. O Ministério da Saúde lançou o texto Propostas e Diretrizes para os Eixos Temáticos ${ }^{13}$ para subsidiar as discussões durante a Conferência.

Dentre as diretrizes apresentadas, o Ministério da Saúde defendeu a reversão do modelo de gestão da força de trabalho em saúde desenvolvido durante a década de 1990:

“[...] A gestão do trabalho e da educação na saúde é uma das prioridades do SUS nesse Governo;

Implementação de uma Política de Desprecarização do Trabalho em Saúde em que os vínculos trabalhistas e previdenciários não são respeitados;

Plano de Carreira, cargos e salários do SUS, o trabalho no SUS passe a ser encarado como Carreira de Estado;

Desenvolvimento de ações e criação de instrumentos que visem à humanização das condições e das relações de trabalho e entre profissionais e usuários; [...]" (www. 〈www.datasus.gov.br/conselho/conselho/htm>)

As propostas do Ministério da Saúde, de efetivação de uma Política de Desprecarização do Trabalho em Saúde, caminham na contramão da reforma informal (NOGUEIRA, 1996) realizada na gestão da força de trabalho ao longo da década de 1990, isto é, de precarização da força de trabalho em saúde e a consequiente fragilização do funcionamento do SUS.

Tal posicionamento indica a intenção de romper com uma concepção 
privatista da política de saúde e parece visar ao fortalecimento dos preceitos instituídos pela Constituição Federal de 1988 e pela Lei Orgânica de Saúde, de 1990.

Contudo, realizar a passagem da intenção para a ação requer um longo e árduo percurso, que envolve, além do gestor federal, os gestores estaduais e municipais, e, é claro, usuários e profissionais de saúde em todos os níveis. Contamos, ainda, com forças políticas radicalmente dissonantes daquela intenção e que se beneficiaram da implementação da reforma informal ao longo da última década, principalmente o setor privado dos planos de saúde.

Tais afirmações, porém, merecem maior aprofundamento e o acompanhamento do percurso de passagem da intenção para a ação. Após o $15^{\circ}$ aniversário do Sistema Único de Saúde, cabe aos sujeitos interessados no fortalecimento de uma saúde pública, gratuita e de qualidade, acompanhar e monitorar, com os recursos disponíveis, as intenções do atual governo para a concretização dos preceitos constitucionais.

\section{Referências}

BEHRING, E. R. A contra-reforma do Estado no Brasil. Rio de Janeiro: UFRJ/ESS, 2002. Mimeo.

BITTENCOURT, S. A participação das cooperativas em licitações públicas. Rio de Janeiro: Temas e Idéias, 2001.

BRASIL. Constituição (1988). Constituição da República Federativa do Brasil: promulgada em 5 de outubro de 1988. São Paulo: Saraiva, 2000.

. Lei $\mathrm{n}^{\mathrm{o}} 8.080 / 90$, de 19 de setembro de 1990. Dispõe sobre as condições para a promoção, proteção e recuperação da saúde, a organização e o funcionamento dos serviços correspondentes e dá outras providências. Diário Oficial da República Federativa do Brasil, Brasília, 20 set. 1990.

. Lei $\mathrm{n}^{\mathrm{o}} 8.142 / 90$, de 28 de dezembro de 1990. Dispõe sobre a participação da comunidade na gestão do Sistema Único de Saúde (SUS) e sobre as transferências intergovernamentais de recursos financeiros na área da saúde e dá outras providências. Diário Oficial da República Federativa do Brasil, Brasília, 30 dez. 1990.

BRAVO, M. I. S.; MATOS, M. C. A reforma sanitária e a contra-reforma na 
saúde. Universidade e Sociedade, n. 22, p. 20-45, 2000.

CARVALHO, M. C. B.; NETTO, J. P. Cotidiano: conhecimento e crítica. São Paulo: Cortez, 1994.

CASTRO, J. L. Nova agenda para a administração de recursos humanos de saúde. In: SANTANA, P.; CASTRO, J. L. (Org.). Capacitação em desenvolvimento de recursos humanos de saúde. Natal: EDUFRN, 1999. p. 341-346.

CHERCHGLIA, M. L. Terceirização do trabalho nos serviços de saúde: alguns aspectos conceituais, legais e pragmáticos. In: SANTANA, P.; CASTRO, J. L. (Org.). Capacitação em desenvolvimento de recursos humanos de saúde. Natal: EDUFRN, 1999. p. 367-385.

CONSELHO NACIONAL DE SAÚDE. Efetivando o SUS: acesso, qualidade e humanização na atenção à saúde, com controle social. Relatório Final da XI Conferência Nacional de Saúde. Brasília, 2001. Disponível em <www.datasus.gov.br/conselho/conselho/htm>. Acesso em abril 2004.

CONSELHO REGIONAL DE SERVIÇO SOCIAL. Lei Orgânica de Assistência Social. Gestão Pro Que Der e Vier 1999-2002. Assistente Social: ética e direitos. Coletânea de Leis e Resoluções. Rio de Janeiro: CRESS, 2000.p. 196-217.

ESCOLA NACIONAL DE SAÚDE PÚBLICA. O Brasil diz como quer ser tratado: XI Conferência Nacional de Saúde. Radis: Comunicação em Saúde, Rio de Janeiro, jan./fev. 2001.

GIRARDI, S. N. Aspectos do(s) mercado(s) de trabalho em saúde no Brasil: estrutura, dinâmica, conexões. In: SANTANA, P.; CASTRO, J. L. (Org.). Capacitação em desenvolvimento de recursos humanos de saúde. Natal: EDUFRN, 1999. p. 125-150.

. Flexibilização dos mercados de trabalho e escolha moral. Revista Divulgação em Saúde para Debate, n. 14, p. 23-32, 1996.

GONÇALVES, W. Parecer sobre terceirização e parcerias na saúde pública. Brasília: Ministério da Saúde, 1998. Disponível em <www.pessoalsus.inf.br>. Acessado em julho 2003.

KOSIK, K. Dialética do concreto. Rio de Janeiro: Paz e Terra, 1976. 
MACHADO, M. H. As profissões e o SUS: arenas conflitivas. Revista Divulgação em Saúde para Debate, n. 14, p. 44-47, 1996.

. O mercado de trabalho em saúde no Brasil: estrutura e conjuntura. Rio de Janeiro: ENSP, 1992.

MAREAgências Autônomas - Projeto de Reforma Administrativa das Autarquias e Fundações Federais do Setor de Atividades Exclusivas do Estado Junho, 1996.

MÉDICI, A C.; GIRARDI, S. N. Emprego, remuneração de pessoal e produtividade em saúde: um balanço da literatura recente. Revista Divulgação em Saúde para Debate, n. 14, p. 38-43, 1996.

NOGUEIRA, R. P. Estabilidade e flexibilidade: tensão de base nas novas políticas de recursos humanos em saúde. Revista Divulgação em Saúde para Debate, n. 14, p. 18-22, 1996(b).

. Política de recursos humanos para a saúde: questões na área da gestão e regulação do trabalho. In: SANTANA, P.; CASTRO, J. L. (Org.). Capacitação em desenvolvimento de recursos humanos de saúde. Natal: EDUFRN, 1999. p. 443-450.

Reforma do Estado, o SUS em reforma e os recursos humanos. In: SANTANA, P.; CASTRO, J. L. (Org.). Capacitação em desenvolvimento de recursos humanos de saúde. Natal: EDUFRN, 1999(b). p. 65-81.

PAIM, J. S. Recursos humanos em Saúde no Brasil: problemas crônicos e desafios agudos. São Paulo: Faculdade de Saúde Pública/USP, 1994.

PEREIRA, L. C. B. Estratégia e estrutura para um novo Estado. Revista de Economia Política, v. 17, n. 1, p. 1-15, 1997. Disponível em <www.rep.org.br>. Acessado em abril 2004.

PEREIRA, L. D. Condições de trabalho, saúde e serviço social: uma radiografia dos seus limites e possibilidades. 2002. Dissertação (Mestrado em Serviço Social) - Escola de Serviço Social, Universidade Federal do Rio de Janeiro, 2002.

SANTANA, J. P. A gestão do trabalho nos estabelecimentos de saúde: elementos para uma proposta. In: SANTANA, P.; CASTRO, J. L. (Org.). Capacitação em desenvolvimento de recursos humanos de saúde. Natal: EDUFRN, 1999. p. 387-400. 
. Recursos humanos: desafios para os gestores do SUS. Revista

Divulgação em Saúde para Debate, n. 14, p. 33-36, 1996.

TRIBUNAL SUPERIOR DO TRABALHO. Enunciado: contrato de prestação de serviços - Legalidade. Súmula ${ }^{\circ}$ 331: revisão do enunciado ${ }^{\circ}{ }^{2} 256$. In: BITTENCOURT, S. A participação das cooperativas em licitações públicas. Rio de Janeiro: Temas e Idéias, 2001. Anexos.

VIEIRA, A L. S. (Org.). Trabalhadores de saúde em números Rio de Janeiro: FIOCRUZ, 1998.

\section{NOTAS}

${ }^{1}$ Assistente Social, doutoranda em Serviço Social pelo Programa de Pós-graduação da Escola de Serviço Social, Universidade Federal do Rio de Janeiro. E-mail: larissadahmer@hotmail.com.

2 "No Brasil, a importância e a dimensão do setor pode ser destacada e avaliada ao se considerar que o mesmo se encontra estruturado em uma rede de quase cinqüenta mil estabelecimentos de saúde, com mais de quinhentos mil leitos e absorvendo em torno de um milhão e quinhentos mil trabalhadores" (VIEIRA, 1998, p. 9).

${ }^{3}$ A Constituição Federal de 1988 organizou-se de forma que seus artigos, como o da Ordem Social, necessitassem de leis orgânicas para serem executados. E as leis orgânicas, por sua vez, necessitam de normas operacionais, que viabilizem a sua operacionalização. No entanto, o entrave não é legal/ jurídico-formal, mas passa pelo plano político. Assim, não há vontade política no Congresso brasileiro - explicitamente alinhado à política governista (neo)liberal na década de 90 - para a efetivação de tais normas, como é o caso da Norma Operacional Básica de Recursos Humanos na Área de Saúde.

${ }^{4}$ Lembremos o posicionamento dos participantes da XI Conferência Nacional de Saúde acerca de tal questão: "A dificuldade do debate se evidencia pela demora na elaboração da NOB de Recursos Humanos, deliberada na X CNS, em 1996, e que se encontra em sua terceira versão, carregada de polêmicas" (CNS, 2001).

${ }^{5}$ Discordamos das teses defendidas pelo autor no que diz respeito à formatação do SUS, pois o mesmo está em clara consonância com o projeto de Reforma do Estado nos moldes liberais. No 
A Gestão da Força de Trabalho em Saúde na Década de 90

entanto, sua leitura é válida, principalmente para a apreensão do discurso dominante e legitimador das políticas para a área de saúde pública nos anos 90. Assim nos fala Nogueira (1999b, p. 79): “[...] a despeito dos constantes protestos dos partidos de esquerda e dos repetidos processos judiciários que alegam inconstitucionalidade, as iniciativas da reforma informal vão avançando cada vez mais com mais ousadas modificações nas formas de operar das instituições estatais".

6 “[...] o SUS vem praticando uma variada gama de formas de terceirização do trabalho nos anos 90. [...], destacam-se a contratação de prestação de serviços de atividades típicas da área da saúde, através de entidades de direito público ou privado, incluindo as associações comunitárias (programas de saúde da família e de agentes comunitários), os clubes de serviços/maçonaria para gerenciarem unidades públicas de saúde e, especialmente, através de cooperativas de serviços e trabalho e a locação de mão-de-obra através de empresas de fornecimento de trabalho temporário [...]. As vendas de serviços profissionais e técnicos, geralmente, são realizadas por cooperativas de trabalho, que, inicialmente, restritas a determinadas especialidades médicas, tendem, nos dias de hoje, a generalizar-se, organizando serviços de outros profissionais" (CHERCHGLIA, 1999, p. 374).

7"Estima-se que de 3.000 a 4.000 servidores [...] vêm-se afastando anualmente pela via da aposentadoria precipitada pelas expectativas negativas em relação à reforma previdenciária, restando menos de 50.000 em atividade" (NOGUEIRA, 1999, p. 445).

${ }^{8}$ Cf. <www. pessoalsus.inf.br>.

${ }^{9}$ Cf. Plano Estratégico para uma Reforma Emergencial do Estado, enviado ao Congresso Nacional no início do Governo Fernando Henrique Cardoso, que afirmava o Estado como mero financiador e agenciador de políticas, dentre elas, a área da saúde como uma atividade não-exclusiva do Estado (MARE, 1996).

${ }^{10}$ Os ideais cooperativistas datam do século XIX, como uma forma de reação dos trabalhadores à exploração imposta através da Revolução Industrial.

${ }^{11}$ Cf. "A questão das falsas cooperativas (cooperativas de fachada ou 'coopergatos')" (BITTENCOURT, 2001).

${ }^{12}$ Para se apreender a discussão sobre a relação essência x fenômeno, vale a leitura de Kosik (1976), particularmente a primeira parte - "Dialética da Totalidade Concreta". Para a leitura sobre a crítica da vida cotidiana, indicamos Carvalho e Netto (1994), especificamente a segunda parte, escrita por Netto: "Para a crítica da vida cotidiana".

${ }^{13}$ Cf. texto do Ministério da Saúde: "Propostas e Diretrizes para os Eixos Temáticos" (<www.12conferencia.com.br >). Até o primeiro semestre de 2004, não havíamos tido acesso ao Relatório Final da XII Conferência Nacional de Saúde. 
Health Sector Workforce Management in the 1990s

This paper provides an overview of public health sector workforce management at the Brazilian national level in the 1990s. The issue is approached in light of widespread outsourcing, considered the most problematic trend in the undermining of the Brazilian public sector and its workforce management. The 1990s were characterized by a loss of the social gains written into the 1988 Brazilian Constitution. Through a literature review, the study seeks to grasp how the casualization of labor relations took place in the public health field during the decade, through a set of strategies including disruption of workers' organization and disqualification of public services, which some authors have referred to as informal reform of the public sector in the public health field. The article concludes with observations on the possibilities for reversing this trend during the Lula Administration, with the affirmation of quality public services, free of cost, in public health.

Key words: Public health; workforce; outsourcing.

Recebido em: 14/06/2004.

Aprovado em: 02/09/2004. 